\title{
ANALISA PERBANDINGAN DIFERENSIASI PRODUK PADA RADUSA.CO DAN MAPLE_ID
}

\author{
Merita Bernik ${ }^{1}$, Thifal Al Thavia Dwinandita ${ }^{2 .}$ \\ ,E-mail: merita.bernik@unpad.ac.id \\ Fakultas Ekonomi dan Bisnis, Universitas Padjadjaran, Jln Dipati Ukur no 35, \\ Bandung,Indonesia
}

\begin{abstract}
In Indonesia the fashion business developments take place quite rapidly. Along with the increased efforts in the field of fashion, causing competition among entrepreneurs engaged in the same field. Various strategies drawn up by the employers in order to win or retain its position as market leader. There are many businesses especially fashion handbags are such change or modify the appearance of the product. When talking about the uniqueness of bags for teenagers and adults may employers bag will compete to create innovative products to create a variety of sizes and colors, unlike the case with the children's work unique bags are bags production Radusa Company and Maple Indonesia. The objective of this study was to compare product differentiation of Radusa Company and Maple Indonesia and to know that consumers have been able to identify well the product differentiation that had been produced compared to their competitors The research method used is a mix method that is quantitative method and qualitative method, to be able to describe a certain condition about product differentiation at Radusa Company and Maple Indonesa. The sampling technique used is nonprobability sampling with purposive method, where the sample is the consumer who is at least 16 years old. For each company taken a sample of 30 consumers. The results of this study indicate that the outline of Radusa Company has differentiated the product in terms of shape, quality of performance, suitability of quality, durability, reliability, ease of improvement and style. While Maple Indonesia has a differentiation of products viewed from the form, features, quality performance, quality conformance, durability, reliability, ease of improvement and style. Based on the respondent's statement about the comparison of product differentiation and Wilcoxon test, it is found that Radusa Company is better than Maple Indonesia
\end{abstract}

Keywords: Product Differentiation, Fashion, Compariso

\section{ABSTRAK}

Di Indonesia perkembangan usaha fashion berlangsung cukup pesat. Seiring dengan meningkatnya usaha-usaha dibidang fashion, menyebabkan terjadinya persaingan diantara pengusaha-pengusaha yang bergerak dibidang yang sama. Berbagai strategi disusun oleh para pengusaha guna memenangkan atau mempertahankan posisinya sebagai pemimpin pasar. Ada banyak usaha-usaha fashion khususnya tas yang sedemikian rupa merubah atau memodifikasi tampilan produknya. Jika berbicara mengenai keunikan tas untuk kalangan remaja dan dewasa mungkin para pengusaha tas akan saling bersaing untuk membuat inovasi produk dengan membuat ukuran dan warna yang beragam, beda halnya dengan tas unik karya anak bangsa yaitu tas produksi Radusa Company dan Maple Indonesia. Tujuan dari penelitian ini untuk membandingkan diferensiasi produk dari Radusa Company dan Maple Indonesia dan untuk mengetahui bahwa konsumen sudah dapat mengidentifikasi dengan baik diferensiasi dari tas yang diproduksi dibandingkan dengan pesaingnya. Metode penelitian yang digunakan adalah mix method yaitu metoda kuantitatif dan metoda kualitatif, untuk dapat menggambarkan atau menguraikan suatu kondisi tertentu mengenai diferensiasi produk pada Radusa Company dan Maple Indonesa.

Kata kunci: Diferensiasi Produk, Fashion, Perbandingan 


\section{PENDAHULUAN}

Di Indonesia perkembangan usaha fashion berlangsung cukup pesat meskipun keadaan perekonomian di Indonesia sedang mengalami masa yang cukup sulit pada saat sekarang ini. Seiring dengan meningkatnya usaha-usaha dibidang fashion, menyebabkan terjadinya persaingan diantara pengusaha-pengusaha yang bergerak dibidang yang sama. Setiap pengusaha berusaha untuk meningkatkan kualitas produknya maupun manajemen pemasarannya dengan tujuan memaksimalkan keuntungan sesuai yang dinginkan setiap pengusaha.

Berbagai strategi disusun oleh para pengusaha guna memenangkan atau mempertahankan posisinya sebagai pemimpin pasar. Untuk mewujudkan hal tersebut pengusaha dituntut untuk bersikap lebih tanggap dan aktif dalam membaca pasar agar mempertahankan dan tercapainya tujuan-tujuan perusahaan. Hal tersebut dapat terwujud dengan melakukan berbagai tindakan nyata seperti mencari konsumen baru, meningkatkan pelayanan kepada konsumen baik sebelum dan sesudah transaksi, dan menjadikan kualitas produk lebih unggul dari pesaing.

Ada banyak usaha-usaha fashion khususnya tas yang sedemikian rupa merubah atau memodifikasi tampilan produknya dari mulai memberi nama, warna, bahkan keragaman motif yang jarang ditemukan di sebuah produk tas, hal ini pun menjadi modal utama untuk menciptakan ciri khas agar produk mudah diingat dibenak pelanggan. Tidak hanya itu biasanya bentuk-bentuk yang dibuat pun semakin unik dan semenarik mungkin.

Radusa Company dan Maple Indonesia, yaitu perusahaan-perusahaan yang memproduksi tas unik di daerah Bandung yang telah mengembangkan produk inovasi dari tas itu sendiri. Mereka saling bersaing untuk membuat tas menjadi terlihat lebih unik, simpel dan memiliki karakteristik tersendiri. Tas yang diproduksi Radusa Company ini memiliki daya tarik produk dari tampilannya.
Salah satunya produk yang paling banyak disukai konsumen adalah Kalimantan Bag, yang mana produk ini memiliki bentuk seperti tabung dengan satu tali yang diberi aksen kayu dan memadukan kanvas polos dengan motif tenun khas Samarinda. Selain itu, diferensiasi produk merupakan strategi yang diperlukan untuk menjadikan daya tarik yang berbeda dengan pesaing. Salah satu pesaing Radusa Company yaitu Maple Indonesia. Keunikan yang dibuat oleh Maple Indonesia berbeda dengan keunikan dari produk Radusa Company.

Maple Indonesia merupakan perusahaan yang membuat tas dengan bentuk yang unik dan praktis digunakan dengan tujuan membuat pemakai lebih terlihat simple dan casual. Tetapi dibalik karakternya yang simple mereka membuat produk tersebut memiliki manfaat yang lebih untuk para pengguna tas Maple Indonesia, yaitu dengan memberi beberapa ruang untuk barang - barang di dalam tas agar memudahkan pengguna ketika menyimpan atau mengambil barang dari dalam tas.

Kedua perusahaan tersebut memiliki berbagai diferensiasi produk diantaranya bentuk, ukuran, nama, warna dll. Keunikan dan ketepatan konsep suatu produk dapat menjadikan perusahaan unggul dalam persaingan. Hingga saat ini, Radusa Company dan Maple Indonesia terus melakukan perkembangan produk baik panjangnya maupun kedalamannya. Menurut Fandy Tjiptono (2011:39), berpendapat bahwa bauran pemasaran merupakan seperangkat alat yang dapat digunakan pasar untuk membentuk karakteristik barang atau jasa yang ditawarkan kepada pelanggan.

Sedangkan menurut Philip Kotler dan Amstrong (2014:76), "Bauran pemasaran adalah kumpulan alat pemasaran taktis produk, harga, tempat dan promosi - yang dipadukan perusahaan untuk menghasilkan respon yang diinginkannya di pasar sasaran. "Produk adalah segala sesuatu yang dapat ditawarkan ke pasar untuk mendapatkan perhatian, dibeli, dipergunakan atau dikonsumsi dan yang dapat memuaskan 
keinginan atau kebutuhan.” Daryanto (2013:52)

Suatu perusahaan harus berusaha mengidentifikasi cara - cara yang spesifik untuk mendiferensiasikan produknya agar mencapai keunggulan kompetitif. Maksudnya perusahaan harus dapat mendeferensiasikan produknya agar perusahaan tersebut memiliki keunikan yang dinilai penting oleh konsumen. Menurut Gunawan (2010:118), "Diferensiasi adalah upaya untuk merancang seperangkat pembeda atau atribut produk fisik untuk membedakan produk perusahaan dengan produk pesaingnya".

Sedangkan menurut Kotler dan Armstrong (2014:214), "Diferensiasi sebagai "actually differentiating the market offering to create superior customer value" artinya tindakan merancang serangkaian perbedaan dalam menawarkan pasar agar memiliki nilai yang tinggi dimata pelanggan".

Berdasarkan pada uraian di atas, maka akan dilakukan perbandingan diferensiasi produk antara Radusa Company dengan Maple Indonesia.

\section{METODE PENELITIAN}

Metode yang diperguanakan adalah mix method yaitu metoda kuantitatif dan metoda kualitatif. Metode kualitatif merupakan hasil dari penyebaran kuesioner dan juga wawancara yang kemudian dioleh dengan menggunakan metoda deskriptif yang bertujuan untuk mencari kesimpulan dengan cara menggambarkan atau menguraikan suatu kondisi tertentu mengenai diferensiasi produk pada Radusa Company dan Maple Indonesia. Sedangkan metoda kuantitatif mempergunakan data hasil penyebaran kuesioner kepada konsumen, yang kemudian data tersebut dipergunakan untuk membandingkan diferensiasi produk dari kedua perusahaan dengan mengunakan uji wilcoxon.

Hipotesis
Ho: $\mathrm{d} \geq 0$ (Diferensiasi produk Rodusa Company lebih baik daripada diferensiasi produk Maple Indonesia)

H1: $d<0$ (Diferensiasi produk Rodusa

Company tidak lebih baik daripada

diferensiasi produk Maple Indonesia)

$$
\mathrm{Z}=\frac{T-\left[\frac{1}{4 N(N+1)}\right]}{\sqrt{\frac{1}{24 N(N+1)(2 N+1)}}}
$$

Teknik pengambilan sampel yang digunakan dalam penelitian ini non probabiility sampling dengan metode purposive sampling karena yang diberikan kuesioner adalah orang yang mengetahui dan berpengalaman membeli produk di Radusa Company dan Maple Indonesia. Kriteria responden adalah berumur minimal 16 tahun dengan alasan mempunyai kemampuan untuk memahami dan mengisi kuesioner yang diberikan. Berdasarkan jumlah populasi konsumen dari kedua perusahaan, maka diperoleh sampel sebanyak 30 konsumen dari setiap perusahaan.

\section{HASIL DAN PEMBAHASAN \\ Diferensiasi Produk}

Diferensiasi produk merupakan salah satu kegiatan untuk membedakan produk dari pesaing. Diferensiasi produk sangat penting dilakukan oleh perusahaan untuk dapat memenangkan persaingan pasar. Radusa Company dan Maple Indonesia menyadari akan pentingnya diferensiasi produk, apalagi kedua perusahaan menjadikan produk tas sebagai produk andalannya. Kedua perusahaan sadar pada zaman sekarang semakin banyak pesaing dan semakin ketat pula persaingan industri ini, maka Radusa Company dan Maple Indonesia melaksanakan diferensiasi produk guna memenangkan persaingan dan dapat menarik konsumen lebih banyak untuk membeli produknya.

Diferensiasi Produk pada Radusa Company 
Adapun diferensiasi produk yang di lakukan Radusa Company yaitu:

\section{Bentuk (Form)}

Radusa Company menawarkan beragam model tas yang unik dan menarik. Model dan variasi ukuran yang bermacam-macam menjadi keunggulan tampilan yang ditawarkan oleh Radusa Company. Bentuk dan ukuran tas yang ditawarkan adalah tas persegi panjang yang berkapasitas cukup besar ( $30 \mathrm{~cm}$ x $40 \mathrm{~cm}$ x 10 $\mathrm{cm})$ dengan nama Molucass Bag, tas berbentuk menyerupai tabung yang berukuran tinggi $35 \mathrm{~cm}$ diameter $15 \mathrm{~cm}$ dengan nama Kalimantan Bag, dan tas menyerupai kerucut yang berukuran $30 \mathrm{~cm} \times 38 \mathrm{~cm}$ dengan nama Papua Bag.

2. Kualitas Kinerja (Performance Quality)

Walaupun produk tas dari Radusa Company memiliki model yang unik dan berbeda dari produk tas pada umumnya, tetapi produk tas yang dikeluarkan oleh Radusa Company akan membuat nyaman pengguna. Salah satunya karena menggunakan bahan-bahan yang berkualitas dan sesuai untuk digunakan pada tas. Bahan-bahan tersebut diantaranya polyster, kanvas linen, dan tali karamental yang membuat pengguna tas tetap nyaman ketika memakai tas tersebut.

3. Kesesuaian Kualitas (Conformance Quality) Radusa Company sangat memperhatikan kepuasan konsumen. Hal ini dapat dilihat dari kesesuaian tas dari spesifikasi yang telah dijanjikan oleh Radusa Company. Contohnya seperti model tas yang ditawarkan, ukuran tas, aksesoris-aksesoris yang digunakan pada tas. Semuanya sangat diperhatikan langsung oleh pemilik Radusa Company agar kualitas kesesuaian dari produknya tetap terjaga dengan baik.

\section{Daya Tahan (Durability)}

Produk Radusa Company adalah produk yang dapat digunakan dalam jangka waktu yang lama atau tahan lama. Konsumen dapat menggunakan produk Radusa Company lebih dari 1 hingga 2 tahun. Produk Radusa Company juga memiliki garansi 1 tahun setelah pembelian. Hal ini dikarenakan Radusa
Company sangat perfeksionis dalam proses produksi mulai dari pemilihan bahan baku, proses penjahitan, pemotongan hingga pengukuran produk. Dan hal tersebut telah dibuktikan sendiri oleh pemilik Radusa Company yaitu Achdiat Farid bahwa produknya yang diproduksi tahun 2014 hingga kini masih terlihat baik walaupun sudah sering digunakan. Selain itu produk Radusa Company ini dirancang semaksimal mungkin agar dapat tahan atau tidak mudah basah jika terkena air salah satunya dengan menggunakan bahan inner waterproof furing.
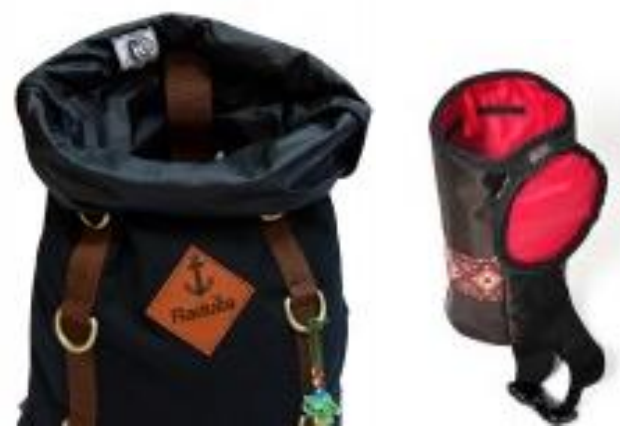

\section{Gambar 1 Contoh bahan Inner Waterproof Furing pada tas Radusa}

Sumber : Radusa Company 2017

5. Kehandalan (Reliability)

Proses produksi semua tas dari Radusa Company diproduksi secara handmade, tidak diproduksi secara masal dan dikerjakan oleh pengrajin yang sudah ahli serta diperhatikan langsung kualitasnya oleh pemilik Radusa Company. Maka dari itu Radusa Company memiliki kehandalan yang baik dan kemungkinan produk ini rusak atau cacat saat diterima konsumen sangat kecil.

6. Kemudahan Perbaikan (Repairability)

Produk Radusa mudah untuk diperbaiki, apabila terjadi kerusakan pada resleting, kain bagian dalam, dan jahitan produk atau bahkan onderdil - onderdil pelengkap pada produk ini dapat dengan mudah diperbaiki di store Radusa terdekat. Selain itu produk yang dijual oleh Radusa Company memiliki garansi setelah pembelian selama 1 tahun, jika kerusakan yang terjadi bukan karena kelalaian konsumen melainkan karena produk yang cacat.

7. Gaya (Style) 
Gaya yang ditampilkan Radusa Company sangatlah unik dan kental dengan kebudayaan Indonesia, karena desain yang ditawarkan sangat berbeda dari produk tas pada umumnya. Gaya yang ditampilkan juga sangat eksklusif karena Radusa Company sangat memperhatikan hal - hal kecil hingga sangat mendetail, seperti model tas yang beragam, keragaman aksesoris dengan menggunakan kayu pinus dari Jerman sebagai salah satunya, motif pada kain-kain khas Indonesiayang dipilih langsung oleh Achdiat sebagai pemilik Radusa Company dan model jahitan yang sangat rapih. Hal ini dipertegas dengan karakter yang berusaha dibentuk oleh Radusa yaitu karakter barang - barang yang bersifat warisan, kuno, unik dan langka.

Dari seluruh variabel yang ada pada diferensiasi produk, Radusa Company tidak menerapkan dua variabel diferensiasi produk, yaitu:

\section{Fitur (Features)}

Untuk saat ini Radusa Company belum menambahkan keistimewaan dari fungsi dasar tas. Produk tas Radusa Company memiliki fungsi pada umumnya. Radusa Company lebih memfokuskan pada tampilan atau desain produk dengan menggunakan bahan-bahan yang berkualitas dan tambahan aksesoris seperti kayu pinus dari Jerman yang diukir langsung oleh tangan-tangan terampil. Untuk kedepannya Radusa Company akan merancang fitur atau keistimewaan dari fungsi dasar tas.

\section{Penyesuaian (Customization)}

Hal ini karena Radusa Company tidak menyediakan layanan custom untuk pembuatan tas yang artinya Radusa Company tidak menerima permintaan-permintaan khusus dari konsumen seperti bentuk tas, warna tas, motif dan lain-lain.
Diferensiasi Produk pada Maple Indonesia Adapun diferensiasi produk yang di lakukan Maple Indonesia yaitu:

\section{Bentuk (Form)}

Tidak kalah dengan Radusa Company yang memiliki beragam model tas yang diproduksi, Maple Indonesia pun memiliki berbagai model tas dan ukuran yang beragam. Maple Indonesia memproduksi tas berbentuk bulan sabit dengan 2 varian ukuran dengan nama Maple Sling Bag, untuk Maple Sling Bag ukuran besar yaitu $50 \mathrm{~cm} \times 26 \mathrm{~cm}$ dengan kapasitas dalam 10L dan Maple Sling Bag ukuran kecil yaitu $40 \mathrm{~cm} \times 22 \mathrm{~cm}$ dengan kapasitas dalam 7L.. Produk tersebut menjadi produk pertama sekaligus produk best seller dari Maple Indonesia. Selain itu Maple Indonesia juga memproduksi Maple Folder Bag yang berbentuk persegi panjang dengan ukuran $32 \mathrm{~cm} \times 23 \mathrm{~cm}$. Pada awal tahun 2017 Maple Indonesia mengeluarkan model tas terbaru yaitu Maple Backpack Bag yang memiliki ukuran $30 \mathrm{~cm} \times 42 \mathrm{~cm}$.

2. Fitur (Features)

Maple Indonesia menawarkan fitur atau keistimewaan lain untuk memvariasikan produknya dari fungsi dasar tas. Fitur tersebut ditonjolkan pada interior atau bagian dalam produk yang unik dan lebih memiliki nilai dibandingkan produk pesaingnya. Di bagian dalam produk Maple Indonesia terdapat ruangruang untuk menyimpan barang-barang berharga sesuai kebutuhan pengguna. Misalnya untuk menyimpan $\mathrm{hp}$, pulpen, charger, dan lain-lain Maple Indonesia sengaja merancang interior produk secara detail selain untuk memberikan keunggulan dari pesaing produk dari Maple Indonesia ini bertujuan memudahkan pengguna dalam beraktifitas dan pada salah satu produknya yaitu Maple Sling Bag diberikan tas kecil tambahan untuk pengguna yang dapat digantung didalam tas . 


\section{Gambar 2 Contoh fitur interior dan bahan kardura yang dimiliki Maple Indonesia}

Sumber : Maple Indonesia 2017

3. Kualitas Kinerja (Performance Quality)

Selain memiliki model tas yang unik, Maple Indonesia sangat memperhatikan kualitas produk yang dijual. Salah satunya bahan yang digunakan, karena Maple Indonesia menggunakan bahan-bahan yang berkualitas dan sesuai untuk digunakan pada tas sehingga produk Maple Indonesia akan nyaman ketika digunakan. Bahan-bahan tersebut diantaranya kardura yang dilapisi busa berkualitas dibagian bahu agar tidak sakit ketika digunakan.

4. Kesesuaian Kualitas (Conformance Quality) Maple Indonesia sangat memperhatikan kepuasan konsumen. Hal ini dapat dilihat dari kesesuaian tas dengan spesifikasi yang telah dijanjikan oleh Maple Indonesia. Contohnya seperti model tas yang ditawarkan, ukuran tas, aksesoris-aksesoris yang digunakan pada tas. Semuanya sangat diperhatikan langsung oleh pemilik Maple Indonesia agar kualitas kesesuaian dari produknya tetap terjaga dengan baik dan konsumen puas dengan layanan yang diberikan oleh perusahaan.

\section{Daya Tahan (Durability)}

Produk Maple Indonesia adalah produk yang dapat digunakan dalam jangka waktu yang cukup lama atau tahan lama jika pengguna mampu menggunakan dan merawat tas tersebut dengan baik karena Maple Indonesia menggunakan bahan-bahan yang berkualitas untuk produknya tersebut. Hal ini dikarenakan Maple Indonesia sangat teliti dalam proses produksi mulai dari pemilihan bahan baku, proses penjahitan, pemotongan pengukuran produk hingga melakukan cek kualitas sebelum produk sampai ditangan konsumen. Produk Maple Indonesia juga tahan atau tidak mudah basah ketika terkena air karena lapisan luar tas menggunakan bahan kardura, Japan drill, dan parakuta yang mampu menahan air agar tidak menyerap. Untuk saat ini produk yang ditawarkan Maple Indonesia tidak memiliki garansi.
Selain Radusa Company, produk Maple Indonesia juga sama tidak memproduksi secara masal melainkan dikerjakan oleh pengrajin yang sudah ahli serta dip

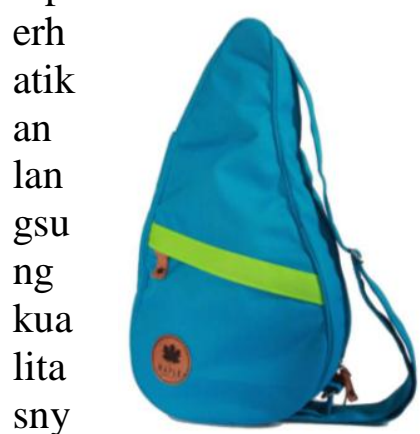

a

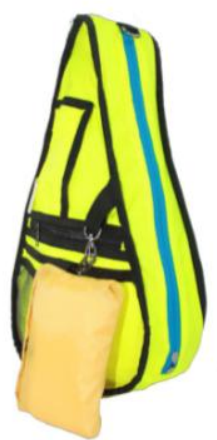

oleh pemilik perusahaan. Maka dari itu Maple Indonesia memiliki kehandalan yang baik dan kemungkinan produk ini rusak atau cacat saat diterima konsumen sangat kecil. Tetapi jika produk yang diterima konsumen rusak atau cacat, maka perusahaan memiliki layanan tukar produk sejenis.

7. Kemudahan Perbaikan (Repairability)

Produk Maple Indonesia memiliki layanan perbaikan produk. Tetapi dikarenakan pada saat ini Maple Indonesia tidak mempunyai store, maka proses pengiriman barang dari konsumen ke pihak Maple Indonesia ataupun sebaliknya tidak mudah. Terdapat beberapa syarat dan ketentuan diantaranya biaya pengiriman ditanggung pihak konsumen, waktu penyelesaian tidak dapat dipastikan, kerusakan produk yang sangat fatal tidak dapat diperbaiki oleh pihak Maple Indonesia, dan lain-lian. Selain itu Maple Indonesia hingga saat ini tidak memiliki garansi pada produk setelah pembelian, tetapi jika kerusakan yang terjadi bukan karena kelalaian konsumen melainkan karena produk yang cacat maka perusahaan memiliki layanan tukar barang sejenis.

8. Gaya (Style)

Gaya yang ditampilkan Maple Indonesia sangatlah simple dan unik, karena desain yang ditawarkan sangat berbeda dari produk tas pada umumnya. Gaya yang ditampilkan juga sangat mewah karena Maple Indonesia selalu mengkombinasikan bahan-bahan standar 
dengan kulit sintetis pada tasnya. Maple Indonesia sangat memperhatikan hal - hal kecil hingga sangat mendetail, seperti model tas, keragaman aksesoris, keragaman warna, motif - motif yang dipilih dan model jahitan.

Dari seluruh variabel yang ada pada diferensiasi produk, Maple Indonesia tidak menerapkan satu variabel diferensiasi produk, yaitu:

Penyesuaian (Customization)

Sama seperti Radusa Company, Maple Indonesia juga tidak menerapkan variabel penyesuaian. Hal ini karena Maple Indonesia tidak menyediakan layanan custom untuk pembuatan tas yang artinya Maple Indonesia tidak menerima permintaan-permintaan khusus dari konsumen seperti bentuk tas, warna tas, motif dan lain-lain.

\section{Hasil Perbandingan Diferensiasi Produk Antara Radusa Company dan Maple Indonesia}

Berdasarkan hasil penyebarn kuesioner terhadap konsumen, maka terdapat hasil skor rata - rata dari setiap perbandingan diferensiasi produk dari kedua produk tersebut yaitu Radusa Company dan Maple Indonesia. Berikut hasil dari tabel skor rata - rata dari setiap poin di atas.

Tabel 1. Hasil Perbandingan Difernsiasi Produk Radusa.CO dan Maple_ID

\begin{tabular}{|l|l|c|c|c|}
\hline N & \multicolumn{1}{|c|}{ Pernyataan } & \multicolumn{2}{|c|}{ Skor } & Selisih \\
\cline { 3 - 5 } O & & $\begin{array}{l}\text { Radu } \\
\text { sa.CO }\end{array}$ & $\begin{array}{l}\text { Mapl } \\
\text { e_ID }\end{array}$ & \\
\hline 1. & $\begin{array}{l}\text { Model tas yang } \\
\text { ditawarkan unik } \\
\text { dan menarik }\end{array}$ & 4,33 & 4,33 & 0 \\
\hline 2 & $\begin{array}{l}\text { Ukuran tas yang } \\
\text { ditawarkan } \\
\text { beragam }\end{array}$ & 3,96 & 4 & 0,04 \\
\hline 3. & $\begin{array}{l}\text { Bagian dalam } \\
\text { tas memiliki } \\
\text { fitur } \\
\text { keistimewaan } \\
\text { dengan }\end{array}$ & 4,63 & 2,67 \\
\hline
\end{tabular}

\begin{tabular}{|c|c|c|c|c|}
\hline & $\begin{array}{l}\text { tersedianya } \\
\text { kantong } \\
\text { tambahan untuk } \\
\text { menyimpan } \\
\text { barang berharga } \\
\text { seperti hp dsb }\end{array}$ & & & \\
\hline 4. & $\begin{array}{l}\text { Produk tersebut } \\
\text { nyaman } \\
\text { digunakan } \\
\text { karena } \\
\text { menggunakan } \\
\text { bahan yang } \\
\text { sesuai untuk tas } \\
\text { dan memiliki } \\
\text { kuatlitas yang } \\
\text { baik }\end{array}$ & 4,2 & 4,4 & 0,2 \\
\hline 5. & $\begin{array}{l}\text { Kualitas produk } \\
\text { yang diterima } \\
\text { konsumen } \\
\text { sesuai dengan } \\
\text { spesifikasi yang } \\
\text { dijanjikan }\end{array}$ & 4,67 & 4,5 & 0,17 \\
\hline 6. & $\begin{array}{l}\text { Produk tersebut } \\
\text { tahan lama }\end{array}$ & 4,2 & 4,3 & 0,1 \\
\hline 7. & $\begin{array}{l}\text { Produk tersebut } \\
\text { dapat tahan atau } \\
\text { tidak mudah } \\
\text { basah ketika } \\
\text { terkena air }\end{array}$ & 4,3 & 4,2 & 0,1 \\
\hline 8. & $\begin{array}{lr}\text { Tas tersebut } \\
\text { memiliki } \\
\text { kehandalan atau } \\
\text { jaminan yang } \\
\text { baik } \\
\text { diterima } \\
\text { konsumen } \\
\text { produk dalam } \\
\text { keadaan tidak } \\
\text { rusak dan cacat }\end{array}$ & 4,8 & 4,76 & 0,04 \\
\hline 9. & $\begin{array}{l}\text { Produk yang } \\
\text { ditawarkan } \\
\text { memiliki garansi } \\
\text { satu tahun } \\
\text { setelah } \\
\text { pembelian }\end{array}$ & 4,6 & 1,26 & 3,34 \\
\hline 10. & $\begin{array}{lr}\text { Spare } & \text { Part } \\
\text { produk } & \text { murah } \\
\text { dan } & \text { mudah }\end{array}$ & 3,73 & 3,56 & 0,17 \\
\hline
\end{tabular}




\begin{tabular}{|c|c|c|c|c|}
\hline & ditemukan & & & \\
\hline 11. & $\begin{array}{l}\text { Warna pada } \\
\text { produk yang } \\
\text { ditawarkan } \\
\text { sangat beragam }\end{array}$ & 4,1 & 4,76 & 0,66 \\
\hline 12. & $\begin{array}{l}\text { Menggunakan } \\
\text { produk tersebut } \\
\text { meningkatkan } \\
\text { kepercayaan diri } \\
\text { anda }\end{array}$ & 4,3 & 4,36 & 0,06 \\
\hline 13. & $\begin{array}{l}\text { Desain produk } \\
\text { tersebut sangat } \\
\text { unik dan } \\
\text { menarik }\end{array}$ & 4,6 & 4,6 & 0 \\
\hline \multicolumn{2}{|c|}{ Rata - Rata Skor } & \multicolumn{3}{|c|}{$\begin{array}{l}\text { Radusa Company }=4,13 \\
\text { Maple Indonesia }=4,12\end{array}$} \\
\hline
\end{tabular}

Sumber : data diolah Penulis (2017)

a. Perbandingan yang cukup signifikan terlihat pada tabel di atas, dapat dilihat perbedaan yang besar dari segi fitur atau keistimewaan pada bagian dalam produk yang terdapat kantong tambahan atau ruang - ruang yang berguna untuk menyimpan barang berharga. Fitur tersebut yang ditawarkan Maple Indonesia mendapatkan skor rata - rata 4,6 dan Radusa Company mendapatkan skor rata - rata 1,93, selisih skor yaitu sebesar 2,67. Hal ini dikarenakan fitur atau keistimewaan pada bagian dalam produk Maple Indonesia lebih menarik dengan adanya kantong tambahan dan ruang - ruang pada bagian dalam tas yang berguna untuk menyimpan barang - barang berharga pengguna dan memudahkan pengguna dalam beraktifitas yang tidak dimiliki oleh pesaingnya yaitu Radusa Company.

b. Perbandingan lain yang signifikan juga terlihat dimana dari segi garansi yang disediakan oleh perusahaan. Radusa Company mendapatkan skor rata - rata 4,6 dan Maple Indonesia mendapatkan skor rata - rata 1,26 , selisih skor yaitu sebesar 3,34. Hal ini dikarenakan produk Radusa Company memiliki garansi satu tahun untuk produk yang memiliki kerusakan yang bukan diakibatkan dari kelalaian pengguna contohnya seperti ketika tas dicuci warnanya menjadi luntur. Hal tersebut tidak dimiliki oleh pesaingnya yaitu Maple Indonesia, perusahaan tersebut belum menyediakan fasilitas garansi satu tahun untuk produk yang dijualnya, tetapi Maple Indonesia menyediakan layanan penukaran produk sejenis jika ketika produk sampai ditangan konsumen produk tersebut dalam keadaan rusak atau cacat, layanan penukaran barang tersebut terbatas waktu yaitu $1 \times 24$ jam setelah pembelian.

c. Pada poin nomor 1 yaitu model tas yang ditawarkan unik dan menarik mendapatkan skor rata - rata yang sama yaitu 4,33. Karena pada dasarnya kedua produk ini yaitu Radusa Company dan Maple Indonesia memiliki model atau bentuk produk yang unik dan jarang ditemui pada produk lain sehingga dapat menarik perhatian konsumen untuk memiliki produk tersebut. Kedua produk tersebut sama - sama memiliki keunikan dalam hal model dimata konsumen tetapi model yang dibuat berbeda, sesuai dengan karakteristik perusahaan masing - masing.

d. Pada poin nomor 13 yaitu desain produk sangat unik dan menarik mendapatkan skor rata - rata sama yaitu 4,6. Hal ini dikarenakan kedua produk yaitu Radusa Company dan Maple Indonesia sangat memperhatikan desain pada produk yang dijual. Tidak hanya model produk tetapi secara keseluruhan desain yang ditampilkan kedua produk memiliki keunikan yang dapat menarik perhatian konsumen. Radusa Company memiliki desain yang unik dan ekslusif karena produk yang dibuat sangat kental dengan unsur kebudayaan Indonesia, salah satunya kombinasi kanvas linen, 
kulit sintetis, kain bermotif suku dayak dan ditambah aksesoris kayu pinus Jerman yang diukir sangat cantik. Sedangkan Maple Indonesia memiliki desain produk simpel, mewah dan ekslusif karena perpaduan antara bentuk yang unik dengan bahan bahan berkualitas seperti kordura dan kulit sintetis yang membuat desain produk terlihat unik.

Sedangkan hasil pengolahan data untuk menguji hipotesis:

Ho: $\mathrm{d} \geq 0$ (Diferensiasi produk Rodusa

Company lebih baik daripada diferensiasi

produk Maple Indonesia)

H1: $d<0$ (Diferensiasi produk Rodusa

Company tidak lebih baik daripada

diferensiasi produk Maple Indonesia)

Diperoleh hasil sebagai berikut:

\section{Wilcoxon Signed Rank Test}

$$
\begin{array}{rl}
\text { variables: } & \text { Rodusa - Maple } \\
180 & \text { sum of positive ranks } \\
171 & \text { sum of negative ranks } \\
& \\
26 & \mathrm{n} \\
175.500 & \text { expected value } \\
39.373 & \text { standard deviation } \\
0.114 & \mathrm{z} \\
& \text { p-value (one-tailed, } \\
.4545 & \text { upper) }
\end{array}
$$

Berdasarkah hasil uji wilcoxon di atas menunjukkan bahwa Ho diterima, hal tersebut menyatakan bahwa diferensiasi produk pada Rodusa Company lebih baik daripada diferensiasi produk pada Maple Indonesia.

\section{KESIMPULAN}

Kesimpulan dari penelitian perbandingan diferensiasi produk Radusa Company dan Maple Indonesia adalah :

1. Diferensiasi produk yang dilaksanakan Radusa Company adalah Bentuk,
Kualitas Kinerja, Kesesuaian Kualitas, Ketahanan, Kehandalan, dan Gaya sedangkan Diferensiasi Produk dari Maple Indonesia terdiri dari Bentuk, Fitur, Kualitas Kinerja, Kesesuaian Kualitas, Ketahanan, Kehandalan, dan Gaya

2. Perbandingan Diferensiasi Produk Radusa Company dan Maple Indonesia berdasarkan hasil perhitungan tanggapan responden, diferensiasi produk yang dilaksanakan Radusa Company dan Maple Indonesia berada pada tingkat "Baik" dengan skor rata rata akhir sebesar 4,13 dan 4,12. Artinya diferensiasi Radusa Company dan Maple Indonesia sudah baik dimata konsumen. Terdapat perbedaan yang cukup signifikan yaitu dari segi fitur atau keistimewaan, Maple Indonesia mendapatkan skor rata - rata 4,6 dan Radusa Company mendapatkan skor rata - rata 1,93. Selain itu perbedaan yang cukup signifikan dilihat dari segi garansi yang disediakan oleh perusahaan, Radusa Company mendapatkan skor rata - rata 4,6 dan Maple Indonesia mendapatkan skor rata - rata 1,26.

3. Dengan menggunakan Wilcoxon test diperoleh hasil bahwa diferensiasi produk secara keseluruhan pada Radusa Compani lebih baik daripada Maple Indonesia, hal tersebut menunjukkan bahwa Radusa Campany harus mempertahankan dan meningkatkan diferensiasi dari produknya, sedangkan untuk Maple Indonesia harus lebih memperbaiki dan juga meningkatkan diferensiasi produknya apabila ingin tetap dapat bertahan dan bersaing dalam dunia fashion terutama tas.

4. Produk dari Rodusa Campany telah teridentifikasi dengan baik oleh konsumennya dibandingkan dengan pesaingnya yaitu Maple Indonesia 


\section{DAFTAR PUSTAKA}

Adisaputro Gunawan. 2010. Manajemen

Pemasaran Analisis Untuk

Perancangan Strategi Pemasaran.

Yogyakarta: UPP STIM YKPN.

Ali Hasan. 2013. Marketing dan Kasus -

Kasus Pilihan. Yogyakarta : CAPS

(Center for Academic Publishing

Service).

Craven, David W, and Nigel F, Piercy. 2006.

Strategic Marketing, 8th edition. New

York: Mc Graw Hill Inc.

Daryanto. 2013. Sari Kuliah Manajemen

Pemasaran. Cetakan II. Januari 2013.

PT. Sarana Tutorial Nurani Sejahtera.

Bandung.

Djaslim Saladin. 2011. Perilaku Konsumen dan Pemasaran strategik. Bandung : Agung Ilmu.

Fandy Tjiptono. 2011. Pemasaran Jasa. Jatim : Bayumedia Publishing.

Kotler, Philip 2009. Manajemen Pemasaran. Edisi 13 Jilid 1. Jakarta : Erlangga.

dan Kevin Keller. 2007.

Manajemen Pemasaran, Edisi Kedua

Belas, Jilid I. Jakarta:PT Indeks.

dan Gary Armstrong. 2012.

Principle of Marketing, 15th edition.

New Jersey : Prentice Hall.

dan Gary Armstrong. 2014.

Principle of Marketing, 15th edition.

New Jersey : Prentice Hall.

dan Kevin Keller. 2016.

Marketing Management, 15th Global

Edition. England : Pearson

Educationn Limited.

Sugiono. 2012. Metode Penelitian Kuantitatif Kualitatif dan Rd. Bandung : Alfabeta. 